\title{
PATHWAYS TO ACADEMIC SUCCESS OF DISADVANTAGED UNDERGRADUATE UNIVERSITY STUDENTS FROM A HIGH-RISK COMMUNITY IN THE WESTERN CAPE ${ }^{1}$
}

\section{Naidoo*}

Masters of Art in Positive Psychology student

http://orcid.org/0000-0003-0146-2082

\section{I. van Schalkwyk* \\ http://orcid.org/0000-0002-8662-0897}

*Africa Unit for Transdisciplinary Health Research (AUTHeR)

North-West University

Potchefstroom, South Africa

\section{ABSTRACT}

Academic success is an indicator of employability and a decreased susceptibility to poverty. South Africa is burdened by high levels of poverty, and low levels of academic achievement. Students in disadvantaged communities such as Delft, in South Africa, typically have poor academic outcomes, since it is linked to socioeconomic status. Despite the myriad of challenges that they encounter, some students from high-risk contexts attain academic success. This study explored the pathways to academic success of disadvantaged university students from a high-risk community in the Western Cape. This qualitative study used a narrative inquiry design. A sample of $10(N=10)$ participants were selected using criterion-based purposive sampling. Data were analysed using thematic analysis. The pathways to academic success have obstacles, but through positive developmental relationships, specific personal qualities, and motivation, the students achieved academic success. The correlation, significance, and impact of each pathway on academic success can be explored further.

Keywords: pathways, undergraduate students, high-risk community, academic performance, positive psychology, resilience, socio-cultural ecologies

\section{INTRODUCTION}

Globally, many adolescents and children face adversity, and the number of challenges and risks appear to be increasing (Theron and Theron 2014, 297; UNICEF 2016, 9). Adversity is the exposure to hardships and challenges as a result of unfavourable social circumstances (Gartland et al. 2019, 1), which include poverty, chronic parental discord, violence, trauma, and ill-health (Theron and Theron 2014, 297; Reddy and Bisin 2017, 12). These challenges pose serious threats for positive development. Childhood experiences of adversity are associated with 
lifelong negative impacts on the social, physical, and mental well-being of individuals (Gartland et al. 2019, 1). The negative spiralling of socio-economic inequality, poverty, and unemployment is associated with a lack of educational outcomes (The World Bank 2018, 45). In contexts of extreme structural disadvantage, such as South Africa, it becomes increasingly vital to safeguard youth from the harmful effects of adversity (Theron and Theron 2014, 297). Education is one such safeguard that has the potential of buffering youth against the negative effects of adversity (Mosang and Van Schalkwyk 2019, 146).

\section{BACKGROUND AND PROBLEM STATEMENT}

Positive academic outcomes are associated with positive mental health and flourishing (Keyes 2005, 539; Khumalo, Temane, and Wissing 2012, 422). Higher education levels are strong predictors for employment and decreased susceptibility to poverty (Naidoo et al. 2019, 667). Employment is recognised in both Western and non-Western societies as a significant contributor to the overall functioning and well-being of individuals (Diener and Ryan 2009, 397; Karabchuk 2016, 232; Sackey 2018, 73; Zhou et al. 2019, 8). According to Rothmann (2013, 128), work has the potential of increasing an individual's well-being across the psychological, social, and emotional well-being domains (see Keyes 2002). Optimal well-being in a work environment can be experienced most notably when individuals experience a sense of competence, self-efficacy, and purpose (Fourie, Rothmann, and Van de Vijver 2008, 38; Jackson, Rothmann, and Van de Vijver 2006, 265; Rothmann 2013, 128). Positive academic progression and attainment are two adequate markers of socioeconomic status that determine employability, income, and influence lifestyle decisions (Khumalo et al. 2012, 422; Naidoo et al. 2019, 667). Education and academic achievement are, therefore, essential buffers against adversity for youth living in disadvantaged areas such as South African, high-risk settings (The World Bank 2018, 45).

South Africa's long history of exposure to political violence, oppression, marginalisation, and poverty (Albien and Naidoo 2018, 147; Savahl et al. 2015, 212) has a significant negative impact on the quality of education that many students ${ }^{2}$ receive (Naidoo et al. 2019, 669; Romero et al. 2018, 31). The aforementioned factors are determinants of each other and perpetuate a snowballing effect of inequality (Banerjee 2016, 13). Furthermore, the low levels of school attrition in South Africa, has resulted in the growth of unemployment (Naidoo et al. 2019, 669). Students in disadvantaged communities such as Delft ${ }^{3}$ in the Western Cape of South Africa, typically have poor academic outcomes, since, according to Wills and Hofmeyr $(2018,2)$, educational outcomes are strongly linked to socioeconomic status.

Delft is one of the 20 high-risk South African communities (Statistics South Africa 2011) 
and is also known as one of the 10 most dangerous areas in South Africa (Crime Statistics South Africa 2018). A high-risk community is an area that lacks adequate infrastructure, resources, employment opportunities, and economic activity (Felner and DeVries 2013, 105). Specific risks in the Delft area are high levels of crime, gangsterism and gangster-related violence, drug trafficking, dysfunctional families (Van Schalkwyk 2019, 3), domestic violence, abusive drinking (May et al. 2013, 818), murder, rape, school dropout, unemployment, and poverty (Crime Statistics South Africa 2018).

Concerns have been expressed about the poor school pass rates and low levels of national numeracy and literacy. Currently in South Africa, approximately 60 per cent of students in Grade one will ultimately drop out of school rather than complete Grade 12, and only 12 per cent of secondary school graduates will be eligible to pursue higher education (Naidoo et al. 2019, 669). In Delft, only 27 per cent of those aged 20 years and older have completed Grade 12 or higher, while 52.3 per cent did not finish secondary school (Statistics South Africa 2011). Academic failure and dropout are pervasive challenges at all levels of the education system (Dupont, Galand, and Nils 2015, 228). Dropping out of school results in low levels of psychological, physical, social, and economic health (Naidoo et al. 2019, 669). Delft's excessive school dropout ratio of more than 52 per cent, is an indicator of low-quality education, becoming "a poverty trap" (Spaull 2015). A lack of academic achievement, specifically, high dropout is one of the drivers of poverty, which perpetuates impoverished settings, numerous social ills, and constant threats for personal well-being.

The dominant approach in current literature on academic achievement follows a problemfocused or deficits model of investigation (Ngalo-Morrison 2017, 18). Research on the academic performance of youth typically focuses on the causes and consequences of academic underachievement and dropout (Alvarez-Roldan, Parra, and Gamella 2018, 116; Heyder, Kessels, and Steinmayr 2017, 206; Ngalo-Morrison 2017, 18; Yesil 2012, 259). Disadvantaged and marginalised students from high-risk communities and low-income families are, therefore, often characterised as vulnerable without considering the assets and resources that may encourage them toward academic success (Abukari 2018, 1).

Studies that approach academic success from a strength or resilience perspective are still limited in an African context (Abukari 2018, 1; Ngalo-Morrison 2017, 40; Theron and Phasha $2015,52)$. While Western studies on academic protective factors are available, they fail to acknowledge the culturally embedded pathways to academic success for students from disadvantaged African societies (Abukari 2018, 1). Subsequently, relatively little is known about the positive processes that operate in the lives of South African students from high-risk communities who manage to achieve academic success despite demographic expectations. The 
current research, therefore, intentionally deliberated how non-Western worldviews can be acknowledged and mobilised to address social issues (Ebersöhn et al. 2018, 2; Mahali et al. 2018, 2).

Disadvantaged contexts with adversities such as poverty and low-resource schools are considered risk factors that threaten student's academic performance (Wills and Hofmeyr 2018, 2). Therefore, understanding how some students manage to overcome the risks to their academic success, may aid in developing knowledge of how to support more students to do the same (Wills and Hofmeyr 2018,3). These authors recommended in-depth qualitative research in similar settings in order to gain such an understanding.

There are some students in South Africa who defy the stereotype that adversity and disadvantaged circumstances preclude academic success. They demonstrate that students from challenging backgrounds can achieve academic success despite improbable circumstances. The present research, therefore, used a strengths-approach, within the framework of positive psychology (PP) to investigate the pathways to academic success of disadvantaged, undergraduate university students from a high-risk community in the Western Cape, South Africa. Pathways refer to those different trajectories that influence academic success. Such an approach, with a bioecological framework, allows for the exploration of proximal processes, personal attributes, culture, history, and the influence of time, within the different life systems of an individual (Rosa and Tudge 2013, 246).

\section{THEORETICAL PERSPECTIVES}

Pathway models emphasise identifying various developmental trajectories that influence a specific sphere in an individual's life (Wright and Masten 2015, 10). The approach allowed for the examination of within-person changes and between-person differences over time, which provided valuable information on processes that serve to produce academic success (Wright and Masten 2015, 10). Since youth live in interlocking systems that are essential to their educational, social, physiological, and psychological development (Gilman et al. 2014, 4), the exploration of pathways to academic success required the use of a bioecological model (Rosa and Tudge 2013, 243).

\section{Personal qualities}

Individual characteristics, strengths, and psychological resources are associated with academic attainment and contribute to the experience of overall well-being (Khumalo et al. 2012, 436; Salmela and Uusiautti 2015, 118). Generative force characteristics, such as grit (Duckworth 2016), character strengths (Peterson and Seligman 2004), self-determination (Ryan and Deci 
2017), positive emotions (Fredrickson 2009) and resource characteristics, such as environmental mastery, autonomy (Keyes 2002), and self-efficacy (Stajkovic et al. 2018) play a vital role in students' pathways to academic success.

\section{Proximal processes}

It is essential to mention that African collectivism is part of the selected high-risk community and the emphasis on the relational nature of goals and needs must be considered (cf. Wilson et al. 2019). In other words, the grounding of the individual's well-being in relationships can enable a better understanding of the social and cultural settings that influence pathways to academic success (Mahali et al. 2018, 3). Subsequently, the proximal processes between the individual and their microsystem could promote well-being, positive development, and academic success.

Although meaningful relationships are central to resilient living, the influence of individual capabilities such as self-regulation and perseverance, are necessary for achievement (Masten 2014, 20). However, Ungar $(2018,23)$ proposes that an individual's internal resources are mitigated if he/she has limited external resources, such as healthy relationships and support from those around them. In a South African study, Theron and Theron $(2014,303)$ found that services such as education do not consistently facilitate resilience processes. Resilience and academic success were only fostered when education services were characterised by active teacher-community connectedness, student responsiveness, and education services providers that went beyond the typical scope of teacher tasks and engaged in supportive actions (Theron and Theron 2014, 301).

\section{Culture and history}

Theron and Phasha $(2015,52)$ show that historical and cultural factors encourage education despite low educational and employment outcomes of parents. For instance, due to the institutionalised inferiority that Bantu education created, educational attainment carries a moral imperative for many Black South Africans. Education is an opportunity for social justice by remedying past inequalities.

In summary, education is an important safeguard against adversity. The history of marginalisation and discrimination in South Africa has led to poor academic outcomes for many students. Poor academic outcomes, unemployment, and inequality have a snowballing effect. Exploring the pathways for academic success of students from disadvantaged backgrounds was, therefore, necessary as it could aid more students to become academically successful as well. There is limited research in a South African context on the positive processes, assets, and 
strengths of students that manage to achieve academic success despite demographic expectations.

\section{AIM AND RESEARCH QUESTION}

This qualitative study aimed to explore and describe the pathways to the academic success of disadvantaged, undergraduate university students from a high-risk community in the Western Cape Province of South Africa. The research question to guide this study was as follows: What are the pathways to the academic success of disadvantaged, undergraduate university students from a high-risk community in South Africa?

\section{METHOD}

\section{Study design}

A qualitative narrative approach was used to explore and describe pathways to the academic success of disadvantaged, undergraduate university students from a high-risk community. A narrative approach focuses on the meaning-making process of experiences and linking the significance of actions and events over time (Chase 2018, 947). Narrative inquiry is appropriate for a small-scale study since it has the capacity to retell stories that have a significant influence on individuals and it addresses issues of cultural complexities (Abukari 2018, 3; Chase 2018, 946). This approach is underpinned by a social constructivist perspective, since constructivism implies that social properties are outcomes of the interaction between individuals and their environment (Bryman 2016, 28). Social constructivism provided a framework to delve into the meanings that the participants attribute to the pathways that helped them to succeed in their academic work.

\section{Participants}

Criterion-based purposive sampling was used to select information-rich cases that were relevant to the research question (Bryman 2016, 324). Information power and data saturation guided the researcher's quest for an adequate sample size (Malterud, Siersma, and Guassora 2016, 1754). Information power specifies that a lower number of participants are required when they hold more relevant information (Malterud et al. 2016, 1754). Accordingly, 10 participants (four females, six males, age range 18-23; see Table 1 for a summary of participant demographics) were selected based on selection criteria such as (a) the participant is studying at a South African university or Higher Education Institution; (b) the participant is aged 18-24 since this age group offers relevant insights into academic success pathways for current Delft school 
students; (c) the participant is receiving a NSFAS bursary; (d) the participant completed his/her Matric at a secondary school in Delft; (e) Delft/high-risk community is still the place of residence for the participant during university recess; and (f) the participant speaks either English or Afrikaans since the research was conducted in these two languages.

Table 1: Participant Demographics

\begin{tabular}{|c|l|c|l|l|l|}
\hline Participant & Sex & Age & Culture & \multicolumn{1}{|c|}{ Degree } & Level of tertiary study \\
\hline 1 & Male & 22 & Coloured & Bachelor of Education & Final year, undergraduate \\
\hline 2 & Male & 22 & Coloured & Bachelor of Education & Final year, undergraduate \\
\hline 3 & Female & 19 & Coloured & Bachelor of Education & 2nd year, undergraduate \\
\hline 4 & Male & 20 & Coloured & $\begin{array}{l}\text { Bachelor of Arts (BA) in } \\
\text { Humanities }\end{array}$ & 2nd year, undergraduate \\
\hline 5 & Female & 18 & Coloured & Bachelor of Education & 1st year, undergraduate \\
\hline 6 & Male & 22 & Coloured & $\begin{array}{l}\text { Bachelor of Science in } \\
\text { Physical Science }\end{array}$ & 1st year, undergraduate \\
\hline 7 & Male & 20 & Xhosa & Bachelor of Law & 2nd year, undergraduate \\
\hline 8 & Female & 22 & Coloured & Bachelor of Education & Final year, undergraduate \\
\hline 9 & Male & 23 & Coloured & Bachelor of Education & Final year, undergraduate \\
\hline 10 & Female & 18 & Xhosa & BA Humanities & 1st year, undergraduate \\
\hline
\end{tabular}

\section{Data collection}

Data were gathered via narrative inquiry, using a demographic questionnaire, a retrospective timeline exercise, and a semi-structured, individual interview. The demographical information indicated the participants' academic achievements, their experience in an academic setting, and their cultural background. The retrospective timeline visualisation exercise was used as a facilitation technique, leading to the generation of richer data about the development of the participants. The visual aid also assisted in gaining greater involvement from the research participants (Comi et al. 2014, 123).

\section{Ethical considerations}

The research proposal was approved by the Health Research Ethical Committee of North-West University (ethics number: NWU-00436-19-S1). Goodwill permission was obtained from a secondary school in Delft to conduct the data collection on the premises and goodwill permission was obtained from a local non-profit organisation to act as a gatekeeper by assisting with the identification of participants. Participants were contacted via email through a mediator who explained the purpose of the research and provided them with an informed consent form. Participants were informed that their participation was entirely voluntary, that they could withdraw at any time without penalty, and they all provided informed consent in the presence of an independent person. Anonymity and confidentiality were assured by the omission of 
participant names through the use of participant numbers. The transcriber and co-coder signed confidentiality agreements. Recordings, transcripts and any other data will be archived at North-West University for six years after the publication of the study, and it will then be destroyed.

\section{Data analysis}

Thematic analysis was used to analyse the timeline transcripts and the semi-structured interview transcripts. It is a theoretically flexible, qualitative method for analysing, identifying, and interpreting patterns of meaning in data (Clarke and Braun 2013, 3) and it is an acceptable method of analysing narratives (McAlpine 2016, 36). Following a narrative approach, the researcher analysed one participant's data at a time, isolating and ordering relevant episodes in a chronological, biographical account (Riessman 2008, 57). The data were then coded, and themes were confirmed using Atlas.ti ${ }^{\mathrm{TM}}$. Examples of codes include academic feedback, extrinsic motivation, collectivism, reliable alliance, and navigating resources. The analysis was approached both inductively and deductively. An inductive approach allowed for the process of pattern identification to answer the research question. A deductive approach guided the analysis in using theory such as the bioecological model to identify key pathways to academic success. The field notes taken by the researcher who collected the data were also compared with the transcripts for additional validation. Furthermore, the researcher invited the participants to a member checking session, five participants attended, for a critical analysis of the initial findings to ensure that the proposed themes reasonably reflected the collected data.

\section{Trustworthiness}

Trustworthiness allows for the replicability of procedures and data generated under different circumstances (Bryman 2016, 302). The presence of credibility, dependability, confirmability, transferability, and reflexivity offer trustworthiness to qualitative research (Creswell and Creswell 2018, 200). Technical accuracy was important in the recording and the transcribing of the data, which aided in the dependability of the research. Interview recordings were transcribed line-by-line; and a co-coder was involved in the data analysis, all of which created a detailed audit trail. Such an audit trail also assisted in the confirmability of the research by accurately reflecting the narratives of the participants, which enables a degree of objectivity. Through the use of detailed descriptions of the research process and purposive sampling, the transferability of the research was increased (Creswell and Creswell 2018, 200). 


\section{FINDINGS}

The themes and sub-themes (see Table 2) that emerged from this qualitative study describe significant milestones and defining moments; they highlight the contributions of key individuals and settings and bring coherence to the journey of academic success for the participants from infancy into early adulthood.

Table 2: Summary of main themes and sub-themes

\begin{tabular}{|l|l|}
\hline \multicolumn{1}{|c|}{ Main theme } & \multicolumn{1}{c|}{ Sub-theme } \\
\hline $\begin{array}{l}\text { A terrible road: Obstacles and potholes on the road to } \\
\text { success }\end{array}$ & \\
\hline Proximal processes on the road to success & $\begin{array}{l}\text { Primary attachment figure } \\
\text { Siblings/Family members } \\
\text { Friends } \\
\text { Teachers } \\
\text { Role model } \\
\text { School and community projects }\end{array}$ \\
& Spirituality \\
\hline Sources of motivation & $\begin{array}{l}\text { Academic rewards motivated future academic } \\
\text { success }\end{array}$ \\
& A context of poverty and a culture of hopelessness \\
& An agent of change \\
& Long-term goals \\
\hline Personal Power & The strength of my character \\
& Self-efficacy \\
\hline
\end{tabular}

\section{A terrible road: Obstacles and potholes on the road to success}

Individuals and their narratives cannot be understood in isolation from their context (Nelson and Prilleltensky 2010,5). All participants in the current study referred to the obstacles and adverse circumstances that they faced on their journey towards academic success. According to participant two, "growing up in Delft, it's difficult and you will always get adversities". Seemingly, hardship is a given for disadvantaged students living in a high-risk community. Such hardships included limited resources, being exposed to community violence, gangsterism, substance abuse, and the disregard for education in the community.

But the adverse circumstances faced by the participants as students in Delft were an important part of their road to academic success. Adversity, according to all of the participants shaped them into the students that they are today and empowered them to rise above the obstacles. Participant nine described it as a "sense of, if I can go through this and through that, I can go through anything in life, man".

\section{Proximal processes on the road to success}

The consensus amongst the participants was that various positive, developmental relationships at different stages in life played vital roles in their academic success. Participant one described 
this so fittingly, "I believe each person in Delft, just needed one person to believe in them, and in their abilities, then they can succeed in life".

Proximal processes, such as positive relationships with various stakeholders and interactions with the school system, were essential for the participants to academically succeed. Each process, such as their school or friends, provided a variety of resources that aided them on their journey to success.

\section{Primary attachment figure}

The primary attachment figures for six of the participants during infancy and middle childhood were their biological parents. Three of the participants described their primary attachment figures during this time as their grandmothers.

The participants who lived with their biological, primary attachment figures during middle childhood explained that their attachment figure(s) played a vital role in taking them to school, teaching them to do homework, providing attachment through expressions of caring and providing reassurance of worth. Homework support during this phase was essential for the participants since participant two explained that, “... after that, we just knew constantly that we always need to sit with our books and stuff like that".

Although the participants with positive primary attachment figures during middle childhood described their support and guidance to establish a strong academic foundation, during secondary school, the guidance from their primary attachment figures decreased. Participant four said, "Obviously my parents was encouraging like from primary school. But when I was much older, I just did my own thing."

Academic success at university is still reliant on the emotional support of attachment figures for five $(50 \%)$ of the participants. Participant three recognised:

"So, if it wasn't for my mom, I would have also dropped out by now ... you need to have that person that will tell you, 'But you can do this,' and then you have to gain that belief in yourself kind of thing again."

\section{Siblings/family members}

Siblings and family members played an essential role on the road to academic success for those participants who did not have academically supportive parents or guardians. Siblings and other family members were often a source of mutual interest, in which the students were encouraged to pursue their academics fervently. Some of the participants described this as academic competition, while others described family members that taught them new skills such as chess, a new language, or critical thinking. 
Other participants experienced a sense of duty and responsibility towards their siblings as frontrunners to academic success. Participant 10 describes this sense of responsibility, "I actually want to be role model for is my sister. I want her to have a real-life role model saying, 'Listen, you can. Like you can. Like there's nothing stopping you'."

\section{Friends}

The role of good friendships was an essential pathway to academic success for the participants. Friendships were a source of safety as participant one explained "... you are with a group of friends. So, you're not feeling alone again" in a high-risk environment.

In addition, friendships in school provided support in the form of social integration since the participants chose “... good friends in high [secondary] school. Like all we had the same all of us had the same mind-set. Like we all wanted to become better, so we like encouraging each other" according to participant five. Eight of the participants described being part of study groups in which friends would academically motivate, encourage, and empower each other. Similar support has continued as an essential part of the participants' university careers. Participant six notes "... the friends at university are there to motivate you now and they're there for you whenever you need that special kind of attention".

\section{Teachers}

Teachers were important for academic success. Every participant described the positive impact that a teacher had on their schooling. In middle childhood, teachers set the foundation for a love of learning by providing positive encouragement and by helping the students develop new skills. Participant five describes such an instance, "My grade one teacher, because I feel like she saw my potential when it comes to like languages and stuff .... And I could spell ... And she was so proud of me, she went to go call the other teachers".

During secondary school, teachers that made the biggest difference were the ones who provided the students with positive academic feedback, reassurance of worth, and abovestandard passing requirements. Participant three suitably summarised this:

"One day I looked at this top ten list and all that kind of stuff. And she [teacher] told me that, 'You can also come there if you want to, and if you put your mind to it'. Then that stay for me for a very long time. And then I actually put myself to that point where I also come there, and that motivates me every time to do better and better."

The teachers who went beyond their typical scope of tasks and provided support in terms of attachment, tangible aid, and guidance were instrumental in creating life defining moments for 
the students. A few teachers also aided the students in applying for university. According to the participants, some teachers visited them at home, and supported them with food, toiletries, and even financial assistance.

Finally, during university, the continuous and meaningful relationships that the teachers established with the students are still evident and the students often rely on the teachers for tangible support in the form of basic needs and academic encouragement.

\section{Role model}

Although there was a distinct lack of role models from the Delft community, the participants were inspired and drew encouragement from role models outside of Delft. Four of the participants were specifically inspired by the words of the former South African president Nelson Mandela who according to participant one said, "Everybody can rise above their circumstances if they are passionate and committed about what they do".

\section{Schools and community projects}

The school setting was another crucial pathway to academic success for the participants. All of the participants explained that their secondary schools, in conjunction with a non-profit organisation (NPO) in the community, provided academic support in the form of extra classes or guidance; they fostered a sense of belonging through after-school clubs; and, they provided opportunities for the students to experience their teachers as approachable through activities such as Fun Days.

The after-school clubs facilitated by the NPO, such as reading club, drama club, dancing club, academic clubs, and choir was exceptionally important at one of the secondary schools that seven of the participants attended. Participant four also described an academic club, at his school that was similar. All of the students explained that these clubs improved their commitment, confidence, academic skills, and friendships. Participant one pointed out that clubs increased his "eagerness to learn". Participant two explained that his "personal belief in [his] own ability to succeed" came from the clubs.

The NPO, has had a tremendous impact on the character development and skills development of the students. Participant eight recollected:

"Club, where you like talked about success and stuff. I saw that, no man, this is very like helpful. Like it teaches how me - helped me as a person, how to like handle challenges. How to handle stuff and how to like develop myself, and how to find myself and how to like being able to like to interact with other people." 
The NPO itself has also provided essential support for the students in terms of academic support and needs satisfaction, such as food, safety, and finances. An important aspect of the NPO that the students valued was the holistic support that they received from the NPO and their constant presence in the community.

\section{Spirituality}

A relationship with God was described as the fuel behind the academic success for most of the participants $(60 \%)$. God and their spiritual lives provided them with hope and strength when they felt that they could not succeed, it encouraged their self-efficacy, and provided a sense of stability in turbulent times. Participant 10 said "Church brings me a whole new sense of peace. For me, if my soul is at peace, then I am able to function through this day."

\section{Sources of motivation}

The third main theme entails the sources of motivation behind the academic progression and success of the participants.

\section{Academic rewards motivated future academic success}

Academic rewards and accolades were mentioned by every participant as a source of motivation for future academic success. All of the participants recounted receiving academic awards in middle childhood or early secondary school, which influenced their belief in their ability to achieve further academic success. Participant six explained that once an individual receives and academic reward, it is the motivation that they need to continue achieving success:

"So that was my pride, I didn't want to back down. I want to keep the - keep on getting that first place .... And I - from that moment onwards, I knew I can do anything. I had the ability to do it. And that's the time when I started to take my life - my academics seriously. And that's just what drive me from the start."

\section{A context of poverty and a culture of hopelessness}

Culture is a significant system that motivated all of the participants to reach academic success, either through goal avoidance or through a sense of duty to those that came before them. For eight of the participants a culture of hopelessness equated the circumstances in the community. Participant nine described the goal avoidance motivation well by stating:

"I think my circumstances was always that thing that really told me, 'No, I don't want this for my future,' you know? I made up my mind at a young age that I'm not going down that way in life, you know? So that was important." 
The legacy of apartheid is still evident in Delft, as Delft was part of the Group Areas Act that racially segregated ethnic groups. The history of marginalisation and a lack of positive educational outcomes were viewed as a source of motivation for several of the participants. At least 50 per cent of them reported that their attachment figures did not have the educational opportunities that they have today. The lack of educational opportunities either took the form of Bantu education or school dropout due to family responsibilities. Participant two said: "So the thing that really fuels me is the unjust that was done to me and to many others". Education has subsequently become a matter of cultural pride. Participant 10 said that, "black parents view a degree as the utmost achievement or rather matric" and participant one stated "I have the duty as a first generational student to break that poverty cycle".

\section{An agent of change}

The community of Delft is mostly an African collectivist society, which is evident in the motivation that the participants have to finish their university qualifications. Every participant expressed a desire and need to come back to Delft after finishing their qualification to use their unique skills, to uplift and give back to the community. They subsequently expressed that keeping this altruistic goal in mind helps them persevere through difficult times. Participant 10 explained that it is about "paving the way for people that are coming after us".

\section{Long-term goals}

The participants all attribute their academic success largely to their long-term goals. Participant three said that if "you know where you want to be in life, you'll actually push yourself to that point”. Every participant had a clear long-term goal that they want to achieve.

\section{Personal power}

Personal qualities and strengths that aided the participants in navigating and negotiating for resources in their environment were central to their academic achievement. Participant one explicated that his "personal strength and character was strong. So again, the foundation was laid. It's just me acting out of what I've learned."

\section{The strength of my character}

The participants displayed and described certain personal qualities and characteristics that are beneficial for academic success. These include bravery, creativity, gratitude, honesty, hope, kindness, leadership, a love of learning, perseverance, determination, perspective, prudence, 
self-regulation, autonomy, a positive mind-set, and self-motivation. Each of these qualities were expanded upon and explained by the students. Honesty, for instance, is important as participant two explains:

“... honesty really is, and it's a really - a secret ingredient, a main ingredient. Because you need to be honest with yourself, what do you want in life? ... So, it's that type of thing where you need to be honest totally with everything. Why did I fail? No, I studied the night before the test."

\section{Self-efficacy}

The belief in one's own ability to achieve success is a major pathway to academic achievement for all of the participants. The findings have indicated that self-efficacy can be cultivated through various proximal processes. It is part of the foundation for a strong academic career since the participants indicated that it was only after gaining confidence in their own academic ability that future success occurred. Participant four explained:

"First of all, I feel like you really have to believe in yourself. That's the first thing. Because if you're not going to believe in yourself, then it's just like you're not going to be able to do anything."

In summary, the pathway to academic success is filled with many obstacles and potholes, but through positive developmental relationships, personal power, and various sources of motivation, the students were able to achieve academic success.

\section{DISCUSSION}

The aim of this study was to explore and describe the pathways to academic success of disadvantaged university students from a high-risk community in the Western Cape. The findings have shown that when students are living in a high-risk community, there are multiple risk factors threatening their academic success. These risk factors can be described in terms of the external environment (cf. Bronfenbrenner 1979). Lazarus, Seedat, and Naidoo $(2017,220)$ indicate, however, that all communities have resources and strengths on which to draw for academic success. It is only when these resources are successfully navigated and negotiated that they have a meaningful impact on academic success (Ungar 2018, 21). The resources or pathways to academic success in a high-risk community navigated by the current participants included positive developmental relationships, contextual motivators, and intrapersonal strengths. 


\section{A terrible road}

Aspects of the students' lives that contribute to resilient coping and academic success are related to one another in patterns that reflect their collectivist culture and high-risk context (Wright and Masten 2015, 15). Amidst the experience of continuous adversity, the field of positive psychology endeavours to enhance well-being by focusing on the strengths and already existing resources that could promote optimal functioning (Wissing 2014, 4). This requires focusing not only on the positive aspects of human functioning but also on the negative experiences inherent in life, so that resilience, specific strengths, and resources required for particular contexts can be identified (Wissing 2014, 4). Resilience, as the capacity of a system to adapt successfully to significant adversities and continue to function healthily and successfully, is particularly appropriate in this setting (Wright and Masten 2015, 4). Academic resilience has been associated with relationships that provide care and support; non-parental sources of support; counsel from peers, siblings, and teachers; intrinsic motivation; academic self-efficacy and positive self-concept; and the availability of community services and organisations (Ungar 2018, 20; Williams et al. 2017, 189).

The adverse circumstances in Delft lead to what Ungar $(2018,21)$ refers to as "well-being undermined". The students in the current research had to intentionally navigate and negotiate the adversities faced in Delft to achieve academic success. The disadvantaged students, showed that constructive reciprocal interactions between an individual and the persons, objects, and symbols in their environment not only diminish dysfunction in adverse circumstances, but also have the capacity to promote outcomes of competence, such as academic success (Bronfenbrenner 2006, 795). The findings of the current research show the vital role of social ecologies for promoting positive adjustment to adverse circumstances (Theron and Theron 2014, 301; Ungar 2011, 1).

\section{Proximal processes}

Families are the primary setting for positive development in middle childhood (Rosa and Tudge 2013, 246). In accordance with Masten $(2014,107)$, the role of primary attachment figures during middle school was essential for promoting achievement and resilience later in life for the current students. The provision of basic needs (Dupont et al. 2015, 229), such as food and safety, guidance and discipline in terms of homework (Miliotis, Sesma, and Masten 1999, 112; Mosang and van Schalkwyk 2019, 144), and academic encouragement in the form of worth reassurance (Koen, Van Eeden, and Rothmann 2013, 159) from primary attachment figures in middle childhood are crucial factors for academic success. However, supportive parents were not the experience of all of the students in the current research. Attachment figures such as 
grandmothers were, therefore, vital for providing academic support that is usually provided by parents. As suggested by Masten $(2014,219)$ the role of these primary attachment figures in academic support lessened in secondary school but did not disappear entirely; such consistent quality relationships are necessary for resilient coping and positive outcomes (Ungar 2011, 1).

Siblings and family members were able to provide support for each other in various forms, such as academic competition, safety, and skills development. Furthermore, the academic motivation provided by younger siblings in the form of responsibility for academic socialisation also had a positive impact on academic success (Wang, Degol, and Amemiya 2019, 1228).

Friendships are influenced by social opportunities and cultural contexts (Major 2012, 128). The associations with like-minded, academically engaged peers positively influenced the student's academic success (Williams et al. 2017, 189). In order to achieve academic success in a high-risk context, it is, therefore, crucial to negotiate for meaningful and positive friendships (Major 2012, 128; Ungar 2011, 4). According to SDT, competence, relatedness, and autonomy are three fundamental human needs that if satisfied lead to optimal functioning (Ryan and Deci 2017, 80). Friendships in the current study were effective in aiding academic success since they were able to fulfil these basic needs (Demir and Davidson 2013, 530).

According to Orrock and Clark $(2018,1020)$ research pertaining to the effects of role models on academic success is mixed and is context dependent. In the current context, South African role models such as Nelson Mandela faced great adversities, but his life example showed the participants that they do not have to be defined by historical discriminations or circumstances. This is especially significant for youth who are breaking historical barriers to academic success by not subscribing to the cognitive limitations imposed on non-white South Africans during apartheid (Branson and Zuze 2012, 69).

The findings of this study highlight the importance of supportive and caring teachers and principals that go beyond their typical scope of tasks for students living in a high-risk area. Teachers played a vital role in aiding the students to navigate the resources they need to succeed in an environment of adversity. Access to material resources, such as financial assistance or university applications by the teachers in the current study, is a crucial factor associated with academic resilience (Ungar 2015, 13). Moreover, positive academic encouragement, a respect for the student's ability, and academic feedback by the teachers had a significant influence on the academic development, self-efficacy, and eventual success for each of the students.

School attachment and commitment are positively correlated to academic achievement (Chowa et al. 2015, 130). The structure, resources, and social atmosphere of a school are often related to student academic success (Chowa et al. 2015, 131). According to Mosang and van Schalkwyk $(2019,146)$, the positive influence of a school in a high-risk community is even 
more vital since they offer various resources for well-being, such as teachers' encouragement toward learning, and resilient coping. Evidently, the schools along with the NPO volunteers contributed to the students' self-efficacy, skills development, and satisfaction of needs. Additionally, they provided the students with a sense of belonging where they could fulfil their need to feel valued and also to add value (Prilleltensky 2019, 2).

Spiritually and religious involvement is an academic success pathway not often mentioned in similar research studies (cf. Chowa et al. 2015; Orrock and Clark 2018; Williams et al. 2017). However, in the current research, spirituality has been shown to be an essential pathway to academic success. Spiritual practices reduce academic stress (Paul and Saha 2016, 48) and are positively related to academic resiliency (Ekwonye and DeLauer 2019, 93).

The interconnectedness of these proximal processes was central to the students' navigation for resources. The presence and interconnectedness of these positive developmental relationships in the student's lives are indicators of high relational well-being (Du Toit, Wissing, and Khumalo 2014, 176; Fredrickson 2009, 21; Keyes 2007, 98; Ryff 1995, 101). Relational well-being contributes to personal well-being (Nelson and Prilleltensky 2010, 35; Ryff and Singer 1996, 15) which in turn contributes to academic success (Howell 2009, 6).

\section{Sources of motivation}

The students were able to draw on both intrinsic and extrinsic forms of motivation to academically succeed. Various forms of motivations were used as sources of to learn, and achieve academic success in school and currently, in university. It is remarkable that students' intrinsic motivation associated with their "internal environment" in the high-risk context comprises also the hardiness to succeed in spite of horrendous disappointments in their external environment.

Academic rewards were associated with the students' constant desire to improve on their academics. Academic rewards bolstered the self-efficacy they needed to academically succeed later in life. In line with the current study, academic praise and rewards have been shown to enhance academic performances (Fefer, DeMagistris, and Shuttleton 2016, 156; Jenkins, Floress, and Reinke 2015, 464).

Avoidance goals, such as the desire not to be impoverished or unemployed or abusing substances, was a significant motivator during school for the students. However, research shows that avoidance goals were negative predictors of eudaimonic well-being (Elliot et al. 2012, 1031). Currently, in university, the students were motivated by historical factors, collectivism, altruism, long-term goals, and a desire to improve their quality of life. Per SDT, extrinsic motivators such as those in middle and secondary school are less sustainable long-term (Ryan 
and Deci 2017, 386). The motivators that were helping the students face difficult academic challenges as university students were those goals that they have internalised and integrated into their repertoire of behaviours to satisfy their needs (Ryan and Deci 2017, 402).

Historical factors have a bidirectional influence on an individual's development (Rosa and Tudge 2013, 243); the students were driven by historical injustices to academically succeed, thereby breaking the intergenerational cycle of poverty, and low educational outcomes which in turn alters the influence of historical factors. The students perceived education as an opportunity to compensate for historic educational inequalities, transcend poverty, uplift families and communities, and bring honour to the African collective; thereby promoting social activism and being agents of change (Theron and Phasha 2015, 52).

Long-term goals and longer-term career planning, as expressed by the students have positive impacts on academic progression and achievement (Naidoo et al. 2019, 679). The findings of the current study were consistent with research studies which suggest that student motivation energises, guides, and sustains academic success-related behaviours (Heyder et al. 2017, 217; Orrock and Clark 2018, 1031; Williams et al. 2017, 192).

\section{Personal strengths and individual character}

Wills and Hofmeyr $(2018,19)$ on the one hand argue that individual factors are significant in predicting positive outcomes. On the other hand, Ungar $(2018,10)$ argues that individual characteristics and traits do not account for the successful attainment of personal goals; they attribute external resources to goal attainment. The current research, using the bioecological model (Bronfenbrenner 2006) showed that both personal qualities and external resources such as proximal processes and cultural influences were essential developmental pathways for goal attainment and academic success.

\section{CONCLUSION}

The pathways to academic success were numerous and multi-faceted; ultimately, academic success for students from a high-risk community required the pursuit and engagement of multiple pathways since many pathways become obscured by adversities. It was vital for students from this high-risk context to know about the academic experiences of their peers who achieved academic success under strenuous circumstances. In this way, the contribution of this study offers possibilities of overcoming educational barriers for millions of South African students to be inspired by relevant role models.

\section{LIMITATIONS}

The findings, while very informative, are limited to the Delft context and can, therefore, not be 
generalised to disadvantaged students in other high-risk communities. The findings of the current research, however, open possibilities for further studies in similar contexts, using the same or similar theoretical underpinnings.

\section{RECOMMENDATIONS}

The pathways revealed several processes and dynamics that each warrant further research. The correlation, significance, and impact of each pathway to academic success can be further explored.

\section{DECLARATION OF INTEREST}

It is my ethical obligation as a researcher, to report that I have an invested interest in the Delft community; I am a voluntary worker for an NPO based in Delft aimed at building resilient youth. My supervisor for the current research is the voluntary NPO director. The research could offer many benefits, such as valuable insight and information, which could direct future NPO activities when building youth resilience. The reflexivity, transferability, dependability, confirmability, and credibility of the research mitigated any potential conflicts of interest.

\section{NOTES}

1. The author has confirmed that an embargo has been placed on the dissertation and it has been removed from the library website of NWU.

2. Student is an umbrella term found in international literature that refers to school learners, undergraduate students, or adolescents studying at an academic/technical institution.

3. The study will only be concerned with participants from this particular community; therefore, the name of the community is made known. The contextualisation of the proposed study is important; therefore, the community cannot be generalised without naming. The researcher implemented recommendations by the NWU ethical committee to protect this community from harm.

\section{REFERENCES}

Abukari, Z. 2018. “'Not giving up': Ghanaian students' perspectives on resilience, risk, and academic achievement." Sage Open 8(4): 1-13. https://doi.org/10.1177/2158244018820378.

Albien, A. and A. V. Naidoo. 2018. "Barriers and enablers for career development among marginalised South African youth." In New perspectives on career counselling and guidance in Europe, ed. V. Cohen-Scali, J. Rossier, and L. Nota, 147-165. Berlin: Springer.

Alvarez-Roldan, A., I. Parra, and J. F. Gamella. 2018. "Reasons for the underachievement and school drop out of Spanish Romani adolescents: A mixed methods participatory study." International Journal of Intercultural Relations 63: 113-127. https://doi.org/10.1016/j.ijintrel.2018.02.001.

Banerjee, P. A. 2016. "A systematic review of factors linked to poor academic performance of disadvantaged students in science and maths in schools." Cogent Education 3(1): 1-17. https://doi.org/10.1080/2331186X.2016.1178441.

Branson, N. and T. L. Zuze. 2012. "Education, the great equaliser: Improving access to quality education." In South African child gauge, ed. K. Hall, I. Woolard, L. Lake, and C. Smith, 69-74. 
Cape Town: Children's Institute, University of Cape Town. https://doi.org/10.1787/eag-2018-en.

Bronfenbrenner, U. 1979. The ecology of human development: Experiments by nature and design. Boston: Harvard University Press.

Bronfenbrenner, U. 2006. "The bioecological model of human development." In Handbook of child psychology: Theoretical models of human development, ed. R. M. Lerner, 793-828. $6^{\text {th }}$ Edition, Volume 1. New York: Wiley.

Bryman, A. 2016. Social research methods. Cape Town: Oxford University Press.

Chase, S. E. 2018. "Toward theoretical and methodological maturity." In The SAGE handbook of qualitative research, ed. N. K. Denzin and Y. S. Lincoln, 946-970. $5^{\text {th }}$ Edition. Los Angeles: Sage.

Chowa, G. A. N., R. D. Masa, Y. Ramos, and D. Ansong. 2015. "How do student and school characteristics influence youth academic achievement in Ghana? A hierarchical linear modeling of Ghana YouthSave baseline data." International Journal of Educational Development 45: 129140. https://doi.org/10.1016/j.ijedudev.2015.09.009.

Clarke, V. and V. Braun. 2013. "Teaching thematic analysis: Overcoming challenges and developing strategies for effective learning." The Psychologist 26(2): 120-123.

Comi, A., N. Bischof, and M. Eppler. 2014. "Beyond projection: Using collaborative visualizations to conduct qualitative interviews." Qualitative Research in Organizations and Management an International Journal 9(2): 110-133. https://doi.org/10.1108/QROM-05-2012-1074.

Creswell, J. W. and J. D. Creswell. 2018. Research design: Qualitative, quantitative, and mixed methods approaches. $5^{\text {th }}$ Edition. Los Angeles: Sage.

Crime Statistics South Africa. 2018. Crime Stats. http://www.crimestatssa.com/topten.php.

Demir, M. and I. Davidson. 2013. "Toward a better understanding of the relationship between friendship and happiness: Perceived responses to capitalization attempts, feelings of mattering, and satisfaction of basic psychological needs in same-sex best friendships as predictors of happiness." Journal of Happiness Studies 14(2): 525-550. https://doi.org/10.1007/s10902-012-9341-7.

Diener, E. and K. Ryan. 2009. "Subjective well-being: A general overview." South African Journal of Psychology 39(4): 391-406. https://doi.org/10.1177/008124630903900402.

Du Toit, M. M., M. P. Wissing, and I. P. Khumalo. 2014. "Positive relationships." In Towards flourishing: Contextualising positive psychology, ed. M. P. Wissing, J. P. Potgieter, T. Guse, T. Khumalo, and L. Nel, 175-219. Pretoria: Van Schaik.

Duckworth, A. L. 2016. Grit: The power of passion and perseverance. New York: Scribner.

Dupont, S., B. Galand and F. Nils. 2015. The impact of different sources of social support on academic performance: Intervening factors and mediated pathways in the case of master's thesis. European Review of Applied Psychology 65(5): 227-237. https://doi.org/10.1016/j.erap.2015.08.003.

Ebersöhn, L., T. Loots, R. Mampane, F. Omidire, M. Malan-Van Rooyen, M. Sefotho, and M. Nthontho. 2018. "An indigenous psychology perspective on psychosocial support in Southern Africa as collective, networking, and pragmatic support." Journal of Community and Applied Social Psychology 28(5): 1-16. https://doi.org/10.1002/casp.2371.

Ekwonye, A. U. and V. DeLauer. 2019. "Exploring individual and interpersonal level factors associated with academic success of college students at a women's, faith-based higher institution." Higher Education Studies 9(1): 86-99. https://doi.org/10.5539/hes.v9n1p86.

Elliot, A. J., C. Sedikides, K. Murayama, A. Tanaka, T. M. Thrash, and R. R. Mapes. 2012. "Crosscultural generality and specificity in self-regulation: Avoidance personal goals and multiple aspects of well-being in the United States and Japan." Emotion 12(5): 1031-1040. https://doi.org/10.1037/a0027456.

Fefer, S., J. DeMagistris, and C. Shuttleton. 2016. "Assessing adolescent praise and reward preferences for academic behavior." Translational Issues in Psychological Science 2(2): 153-162. https://doi.org/10.1037/tps0000072.

Felner, R. D. and M. L. DeVries. 2013. "Poverty in childhood and adolescence: A transactional- 
ecological approach to understanding and enhancing resilience in contexts of disadvantage and developmental risk." In Handbook of resilience in children, ed. S. Goldstein and R. B. Brooks, 105-126. $2^{\text {nd }}$ Edition. New York: Springer.

Fourie, L., S. Rothmann, and F. J. R van de Vijver. 2008. A model of work wellness for non-professional counsellors in South Africa. Stress and Health 24(1): 35-47. https://doi.org/10.1002/smi.1163.

Fredrickson, B. L. 2009. Positivity. New York: Three Rivers Press.

Gartland, D., E. Riggs, S. Muyeen, R. Giallo, T. O. Afifi, H. MacMillan, H. Herrman, E. Bulford, and S. J. Brown. 2019. "What factors are associated with resilient outcomes in children exposed to social adversity? A systematic review." BMJ Open 9(4): 1-14. https://doi.org/10.1136/bmjopen2018-024870.

Gilman, R., E. S. Huebner, and M. J. Furlong. 2014. Handbook of positive psychology in schools. New York: Routledge.

Heyder, A., U. Kessels, and R. Steinmayr. 2017. "Explaining academic-track boys' underachievement in language grades: Not a lack of aptitude but students' motivational beliefs and parents' perceptions?" British Journal of Educational Psychology 87(2): 205-223. https://doi.org/10.1111/bjep.12145.

Howell, A. J. 2009. "Flourishing: Achievement-related correlates of students' well-being." The Journal of Positive Psychology 4(1): 1-13. https://doi.org/10.1080/17439760802043459.

Jackson, L. T. B., S. Rothmann, and F. J. R. van de Vijver. 2006. "A model of work-related well-being for educators in South Africa." Stress and Health 22(4): 263-274. https://doi.org/ 10.1002/smi.1098.

Jenkins, L. N., M. T. Floress, and W. Reinke. 2015. "Rates and types of teacher praise: A review and future directions." Psychology in the Schools 52: 463-476. https://doi.org/10.1002/pits.21835.

Karabchuk, T. 2016. "The subjective well-being of women in Europe: Children, work and employment protection legislation." Mind and Society 15(2): 219-245. https://doi.org/10.1007/s11299-0160194-3.

Keyes, C. L. M. 2002. "The Mental Health Continuum: From languishing to flourishing in life." Journal of Health and Social Behavior 43(2): 207-222. https://doi.org/10.2307/3090197.

Keyes, C. L. M. 2005. "Mental illness and/or mental health? Investigating axioms of the complete state model of health." Journal of Consulting and Clinical Psychology 73(3): 539-548. https://doi.org/10.1037/0022-006X.73.3.539.

Keyes, C. L. M. 2007. "Promoting and protecting mental health as flourishing: A complementary strategy for improving national mental health." American Psychologist 62(2): 95-108. https://doi.org/ 10.1037/0003-066X.62.2.95.

Khumalo, I. P., Q. M. Temane, and M. P. Wissing. 2012. "Socio-demographic variables, general psychological well-being and the mental health continuum in an African context." Social Indicators Research 105(3): 419-442. https://doi.org/10.1007/s11205-010-9777-2.

Koen, V., C. van Eeden and S. Rothmann. 2013. "A model for psychosocial well-being of families in a South African context." Journal of Psychology in Africa 23(1): 155-164. https://doi.org/ 10.1080/14330237.2013.10820611.

Lazarus, S., M. Seedat, and A. V. Naidoo. 2017. "Community building: Challenges of constructing community." In APA handbook of community psychology: Methods for community research and action for diverse groups and issues, ed. M. A. Bond, I. Serrano-García, C. B. Keys, and M. Shinn, 215-234. Volume 2. Washington: American Psychological Association.

Mahali, A., I. Lynch, A. W. Fadiji, T. Tolla, S. Khumalo, and S. Naicker. 2018. "Networks of wellbeing in the global South: A critical review of current scholarship." Journal of Developing Societies 34(4): 1-28. https://doi.org/10.1177/0169796X18786137.

Major, K. 2012. "Friendships: The power of positive alliance.” In Positive relationships: Evidence based practice across the world, ed. S. Roffey, 127-143. Dordrecht: Springer. 
Malterud, K., V. D. Siersma, and A. D. Guassora. 2016. "Sample size in qualitative interview studies: Guided by information power." Qualitative Health Research 26(13): 1753-1760. https://doi.org/10.1177/1049732315617444.

Masten, A. S. 2014. Ordinary magic: Resilience in development. New York: The Guilford Press.

May, P. A., J. Blankenship, A. S. Marais, J. P. Gossage, W. O. Kalberg, R. Barnard, M. De Vries, L. K. Robinson, C. M. Adnams, D. Buckley, M. Manning, K. L. Jones, C. Parry, H. E. Hoyme, and S. Seedat. 2013. "Approaching the prevalence of the full spectrum of fetal alcohol spectrum disorders in a South African population-based study." Alcoholism, Clinical and Experimental Research 37(5): 818-830. https://doi.org/10.1111/acer.12033.

McAlpine, L. 2016. "Why might you use narrative methodology? A story about narrative." Estonian Journal of Education 4(1): 32-57. https://doi.org/doi: 10.12697/eha.2016.4.1.02b.

Miliotis, D., A. Sesma, and A. S. Masten. 1999. "Parenting as a protective process for school success in children from homeless families." Early Education and Development 10(2): 111-133. https://doi.org/10.1207/s15566935eed1002_2.

Mosang, T. and I. van Schalkwyk. 2019. "The perceived role of risk and resilience factors regarding children in middle childhood's psycho-social well-being in a South African rural high-risk community." Journal of Educational and Developmental Psychology 9(2): 138-149. https://doi.org/10.5539/jedp.v9n2p138.

Naidoo, A. V., M. Visser, M. de Wet, S. Rabie, I. van Schalkwyk, M. Boonzaier, G. de Bruin, L. Shirley, and C. Venter. 2019. "A group-based career guidance intervention for South African high-school learners from low-income communities." In Handbook of innovative career counselling, ed. J. G. Maree, 665-685. Switzerland: Springer.

Nelson, G. and I. Prilleltensky. 2010. Community Psychology: In pursuit of liberation and well-being. $2^{\text {nd }}$ Edition. England: Palgrave Macmillan Limited.

Ngalo-Morrison, L. 2017. "Factors influencing the academic attainment of undergraduate sponsored students at the University of the Western Cape: A strength-based approach." Unpublished PhD thesis, University of the Western Cape. http://etd.uwc.ac.za/xmlui/bitstream/handle/11394/5553/ morrison_phd_edu_2017.pdf? sequence $=1$.

Orrock, J. and M. A. Clark. 2018. "Using Systems Theory to promote academic success for African American males." Urban Education 53(8): 1013-1042. https://doi.org/10.1177/ 0042085915613546.

Paul, M. and P. Saha. 2016. "Spirituality as a potential psychological capital tool to deal with academic stress among management students." Journal of Organizational Behavior 15(4): 46-65.

Peterson, C. and M. E. P. Seligman. 2004. Character strengths and virtues: A handbook and classification. Washington: American Psychological Association.

Prilleltensky, I. 2019. "Mattering at the intersection of psychology, philosophy, and politics." American Journal of Community Psychology 0: 1-9. https://doi.org/10.1002/ajcp.12368.

Reddy, S. and S. Bisin. 2017. UNICEF South Africa 2017 highlights, 1-36. Pretoria: Unicef.

Riessman, C. K. 2008. Narrative methods for the human sciences. California: Sage.

Romero, R. H., J. Hall, L. Cluver, and F. Meinck. 2018. "Can supportive parenting protect against school delay amongst violence-exposed adolescents in South Africa?" Child Abuse and Neglect 78: 3145. https://doi.org/10.1016/j.chiabu.2017.09.025.

Rosa, E. M. and J. Tudge. 2013. "Urie Bronfenbrenner's theory of human development: Its evolution from ecology to bioecology." Journal of Family Theory and Reviews 5: 243-258. https://doi.org/10.1111/jftr.12022.

Rothmann, S. 2013. "From happiness to flourishing at work: A Southern African perspective." In Wellbeing research in south Africa, ed. M. P. Wissing, 123-151. New York: Springer.

Ryan, R. M. and E. L. Deci. 2017. Self-determination theory: Basic psychological needs in motivation, development, and wellness. New York: Guilford Press. 
Ryff, C. D. 1995. "Psychological well-being in adult life." Current Directions in Psychological Science 4(4): 99-104. https://doi.org/10.1111/1467-8721.ep10772395.

Ryff, C. D. and B. Singer. 1996. "Psychological well-being: Meaning, measurement, and implications for psychotherapy research." Psychotherapy and Psychosomatics 65(1): 14-23. https://doi.org/ $10.1159 / 000289026$.

Sackey, H. A. 2018. "Rural non-farm employment in Ghana in an era of structural transformation: Prevalence, determinants and implications for well-being." Journal of Rural and Community Development 13(3): 57-77. https://eds-a-ebscohost-com.nwulib.nwu.ac.za.

Salmela, M. and S. Uusiautti. 2015. "A positive psychological viewpoint for success at school - 10 characteristic strengths of the Finnish high-achieving students." High Ability Studies 26(1): 117137. https://doi.org/10.1080/13598139.2015.1019607.

Savahl, S., S. Adams, S. Isaacs, R. September, G. Hendricks, and Z. Noordien. 2015. "Subjective wellbeing amongst a sample of South African children: A descriptive study." Child Indicators Research 8(1): 211-226. https://doi.org/10.1007/s12187-014-9289-8.

Spaull, N. 2015. "Schooling in South Africa: How low-quality education becomes a poverty trap." South African Child Gauge 2015, 34-41. http:/www.ci.uct.ac.za/sites/default/files/ image_tool/images/367/Child_Gauge/South_African_Child_Gauge_2015/Child_Gauge_2015Schooling.pdf.

Stajkovic, A. D., A. Bandura, E. A. Locke, D. Lee, and K. Sergent. 2018. Test of three conceptual models of influence of the big five personality traits and self-efficacy on academic performance: A meta-analytic path-analysis. Personality and Individual Differences 120: 238-245. https://doi.org/10.1016/j.paid.2017.08.014.

Statistics South Africa. 2011. City of Cape Town: 2011 census suburb Delft. http://www.statssa.gov.za/? page_id $=4286$ andid $=313$.

The World Bank. 2018. Overcoming poverty and inequality in South Africa: An assessment of drivers, constraints and opportunities. Washington: The World Bank.

Theron, L. C. and N. Phasha. 2015. "Cultural pathways to resilience: Opportunities and obstacles as recalled by Black South African students." In Youth resilience and culture: Commonalities and complexities, ed. L. C. Theron, L. Liebenberg, and M. Ungar, 51-65. New York: Springer.

Theron, L. C. and A. M. C. Theron. 2014. "Education services and resilience processes: Resilient Black South African students' experiences." Children and Youth Services Review 47: 297-306. https://doi.org/10.1016/j.childyouth.2014.10.003.

Ungar, M. 2011. "The social ecology of resilience: Addressing contextual and cultural ambiguity of a nascent construct." American Journal of Orthopsychiatry 81(1): 1-17. https://doi.org/10.1111/ j.1939-0025.2010.01067.x.

Ungar, M. 2015. Working with children and youth with complex needs: 20 skills to build resilience. New York: Routledge.

Ungar, M. 2018. Change your world: The science of resilience and the true path to success. Toronto: Sutherland House.

UNICEF. 2016. Violence against children in education settings in South Asia: A desk review, 1-84. Kathmandu: Unicef.

Van Schalkwyk, I. 2019. "Strengthening female-headed households: Exploring the challenges and strengths of mothers with substance-problems living in a high-risk community." Journal of Family Studies 25: 1-23. https://doi.org/10.1080/13229400.2019.1584122.

Wang, M. T., J. L. Degol, and J. L. Amemiya. 2019. "Older siblings as academic socialization agents for younger siblings: Developmental pathways across adolescence." Journal of Youth and Adolescence 48(6): 1218-1233. https://doi.org/10.1007/s10964-019-01005-2.

Williams, J. M., J. Bryan, S. Morrison, and T. R. Scott. 2017. "Protective factors and processes contributing to the academic success of students living in poverty: Implications for counselors." Journal of Multicultural Counseling and Development 45(3): 183-200. https://doi.org/ 
10.1002/jmcd.12073.

Wills, G. and H. Hofmeyr. 2018. Academic resilience in challenging contexts: Evidence from township and rural primary schools in South Africa. Stellenbosch: University of Stellenbosch.

Wilson, A., M. P. Wissing, L. Schutte, and I. M. Kruger. 2019. "Understanding goal motivations in deprived contexts: Perspectives of adults in two rural South African communities." Applied Research in Quality of Life 14(1): 113-129. https://doi.org/10.1007/s11482-017-9583-y.

Wissing, M. P. 2014. "Selected theories on functioning well and feeling good." In Towards flourishing: Contextualising positive psychology, ed. M. P. Wissing, J. P. Potgieter, T. Guse, T. Khumalo, and L. Nel, 141-171. Pretoria: Van Schaik.

Wright, M. O. and A. S. Masten. 2015. "Pathways to resilience in context." In Youth resilience and culture: Commonalities and complexities, ed. L. C. Theron, L. Liebenberg, and M. Ungar, 3-22. New York: Springer.

Yesil, R. 2012. "Validity and reliability studies on the scale of the reasons for academic procrastination." Education 133(2): 259-274.

Zhou, Y., M. Zou, S. A. Woods, and C. H. Wu. 2019. "The restorative effect of work after unemployment: An intraindividual analysis of subjective well-being recovery through reemployment." Journal of Applied Psychology 104: 1-12. https://doi.org/10.1037/apl0000393. 